NOTE

\title{
Using itraconazole to clear Batrachochytrium dendrobatidis infection, and subsequent depigmentation of Alytes muletensis tadpoles
}

\author{
T. W. J. Garner ${ }^{1, *}$, G. Garcia ${ }^{2}$, B. Carroll ${ }^{3}$, M. C. Fisher ${ }^{3}$ \\ ${ }^{1}$ Institute of Zoology, Zoological Society of London, Regent's Park, London NW1 4RY, UK \\ ${ }^{2}$ Durrell Wildlife Conservation Trust, Les Augrès Manor, Trinity, Jersey JE3 5BP, UK \\ ${ }^{3}$ Department of Infectious Disease Epidemiology, Imperial College, St. Mary's Campus, Norfolk Place, London W2 1PG, UK
}

\begin{abstract}
Batrachochytrium dendrobatidis $(B d)$ is a global threat to amphibian biodiversity. Current calls for conservation through captive breeding require that efficient and reliable antifungal treatments be developed for target species. Here we confirm that the antifungal itraconazole is an effective treatment for infection in larval Alytes muletensis. Exceptionally low doses applied as few as 7 times were effective at clearing infection from tadpoles for up to $28 \mathrm{~d}$ after treatment. However, we cannot recommend itraconazole as a treatment for this species as depigmentation of tadpoles was observed. Further research is required to determine the putative hepatotoxicity of this treatment.
\end{abstract}

KEY WORDS: Batrachochytrium dendrobatidis $\cdot$ Antifungal treatment $\cdot$ Tadpole $\cdot$ Depigmentation

\section{INTRODUCTION}

Batrachochytrium dendrobatidis $(B d)$ is recognized internationally as a major and global threat to amphibian populations and species; this has resulted in calls for immediate conservation actions that mitigate the impact of disease (Mendelson et al. 2006). Captive populations and breeding are widely cited as necessary steps towards ensuring species conservation, as extinction in the wild due to chytridiomycosis is a strong possibility (La Marca et al. 2005, Schloegel et al. 2006, Skerratt et al. 2007). However, it is becoming increasingly clear that some captive amphibian populations are rife with infection, and suffer catastrophic losses due to chytridiomycosis (Berger et al. 1998, Parker et al. 2002, Fisher \& Garner 2007). It is essential to develop treatment protocols that will allow the Amphibian Ark (www.amphibianark.org/) and other programmes to bring highly threatened species into captivity to cure animals of infection and to maintain $(B d)$-free populations.
Current published treatments include elevated temperature (Woodhams et al. 2003), formalin/malachite green (Parker et al. 2002), salt (White 2006) and standard veterinary antifungals (Marantelli et al. 2000, Nichols \& Lamirande 2000, Hadfield \& Whitaker 2005). Elevating temperature, altering salinity and exposing animals to toxic compounds to treat infection, while effective in some amphibians, are hampered by the physiological constraints of the majority of species, as most amphibians do not respond well to elevated temperature or salinity. Practical constraints associated with regional and international legislation are another consideration. Malachite green intercalates with double-stranded DNA, is a proven mutagen, is presumed to be carcinogenic and is cytotoxic in mammalian cells (Culp \& Beland 1996). For these and other reasons, malachite green is not approved as an aquatic veterinary drug in North America and Europe (Andersen et al. 2004). In comparison, antifungal drugs may be well tolerated by a wide range of amphibian species, especially when used at low concentrations (Pessier 2008). 
However, larvae are highly sensitive to chemicals (Bridges \& Semlitsch 2000, Relyea 2003), and it is not known whether they can survive exposure to typical veterinary drugs at the concentrations required to clear $B d$ infections. Certainly there is a growing interest in treating the larval stages of amphibians, as much mortality reported in field studies occurs at or soon after metamorphosis (Bosch \& Martínez-Solano 2006).

In this paper we describe an experimental investigation of the utility of itraconazole as an antifungal treatment against $B d$ infection in the Mallorcan midwife toad Alytes muletensis. Recent and successful conservation efforts mitigating the effects of invasive predators, competitors and habitat degradation have resulted in the species being downgraded from endangered to vulnerable (IUCN Red List, vulnerable D2), but now chytridiomycosis has emerged in wild populations (Walker et al. 2008). Current estimates place the total number of breeding adults at about 3000 (S. Pinya pers. comm.) and the number of (sub)populations at 30. Existing captive breeding populations have also suffered from chytridiomycosis (Walker et al. 2008), and it is clear that species-specific treatments are urgently required.

\section{MATERIALS AND METHODS}

We selected itraconazole (Itrafungol, Janssen Animal Health) as a possible treatment based on previously published reports (Nichols \& Lamirande 2001) and experience in the veterinary department of the Zoological Society of London (ZSL). The solution of itraconazole used contained only sugars and alcohol solvents (propylene glycol), so all effects measured in the present study should be attributable to the antifungal itself. We used tadpoles produced by the Durrell Wildlife Conservation Trust (DWCT) captive breeding programme, which we have been surveying for infection for several years. A subset of these tadpoles were tested to ensure that study animals were not infected with $B d$ beforehand. We kept all other experimental animals individually in 11 plastic boxes containing $750 \mathrm{ml}$ tap water aged $3 \mathrm{~d}$. Tadpoles were fed $900 \mathrm{mg}$ ground Tetra TabiMin (Tetra $\mathrm{GmbH}$ ) every $3 \mathrm{~d}$, with water changed every 4th day. We exposed tadpoles individually and over the course of $2 \mathrm{wk}$ to 4 doses of a minimum of 5000 active $B d$ zoospores in liquid mTGhL media (minimum $8 \mathrm{~g}$ tryptone, $2 \mathrm{~g}$ gelatin hydrolysate, $4 \mathrm{~g}$ lactose in 11 total volume distilled water).

From previous experience, we had determined what volume of media to box water would not result in bacterial blooms (300 $\mu \mathrm{l}$ in $140 \mathrm{ml})$ : all doses administered were well below this. We used an isolate recovered from a dead common midwife toad Alytes obstet- ricans collected at a mass mortality event in the Pyrenees (M. C. Fisher unpubl. data).

At 2 wk post-infection, 5 individuals were euthanized to assess the efficacy of the infection protocol. The remaining tadpoles were randomly assigned to one of 12 treatments. These included 3 groups of positive controls (infected), each composed of 4 to 5 tadpoles. Positive control groups were euthanized 14, 21 or $28 \mathrm{~d}$ post-treatment and were used to prove the maintenance of infection during the course of the experiment. The other 9 treatments were composed of 6 tadpoles per group and defined by the strength of the itraconazole baths $\left(0.5,1.0\right.$ and $1.5 \mathrm{mg} \mathrm{l}^{-1}$, subsequently referred to as low, medium and high) and the number of days tadpoles were given 5 min baths at their respective concentrations (7,14 or $21 \mathrm{~d}$ of baths). Tadpoles treated with itraconazole were kept an additional week after the final bath exposure before euthanasia. We did this to allow any subclinical $B d$ infections to regenerate after exposure to itraconazole was completed. Euthanasia in all cases was performed using an overdose of buffered MS-222 (5\% tricaine methane sulphonate buffered to $\mathrm{pH} 7$ with standard baking soda). All procedures were done under licence from the Home Office (70/6227) following full ethical review.

Euthanized tadpoles were stored in $70 \%$ ethanol until the end of the experiment. Upon completion of the experiment, the mouthparts of each tadpole were excised, resuspended in $50 \mu$ l of PrepMan Ultra (Applied Biosystems) and extracted following the bead-beating protocol of Boyle et al. (2004). Extractions were diluted $1 / 10$ and amplified using the real time quantitative polymerase chain reaction (qPCR) procedure of Boyle et al. (2004). All qPCRs were performed in duplicate with negative controls and 4 dilutions of concentration standards $(100,10,1$ and 0.1 zoospore genomic equivalents, or GE).

\section{RESULTS}

Tadpoles sourced from DWCT were considered uninfected upon delivery; this population has been screened for several years, and $B d$ was not detected by qPCR from the mouthparts of the 5 reference specimens (T. W. J. Garner unpubl. data). One positive control tadpole died of unknown causes $2 \mathrm{~d}$ after the first dose of $B d$. This individual also tested negative for infection. Results of qPCR assays of positive control specimens taken through the entire infection protocol showed infection was stably maintained throughout the course of the experiment. Prevalence of B. dendrobatidis in positive control groups ranged from 75 to $100 \%$. One of 5 tadpoles euthanized immediately after 
the cessation of infections exhibited no sign of infection, while all others tested positive (mean GE $\pm \mathrm{SE}=15.7 \pm 12.8$ ). Individuals sampled on Day 14 averaged similar levels of infection with 1 of 4 testing negative $(16.6 \pm 14.9)$. The infection burden increased by Day 21 (all 4 tadpoles infected, $29.05 \pm 11.5$ ) and by Day 28 all 4 individuals were infected (41.3 \pm 29.5); however, this increase was not statistically significant (linear regression, $\mathrm{p}=0.27$ ).

In contrast, all tadpoles infected with $\mathrm{Bd}$ and then treated with itraconazole showed a comprehensive lack of detectable infection. All extractions from individuals, treated with the antifungal tested negative for the presence of $B d$, including the 2 tadpoles that died $5 \mathrm{~d}$ before they were due for euthanasia (low dose, $7 \mathrm{~d}$ bath protocol). Tadpoles did not exhibit any stressful behaviour when immersed in the itraconazole

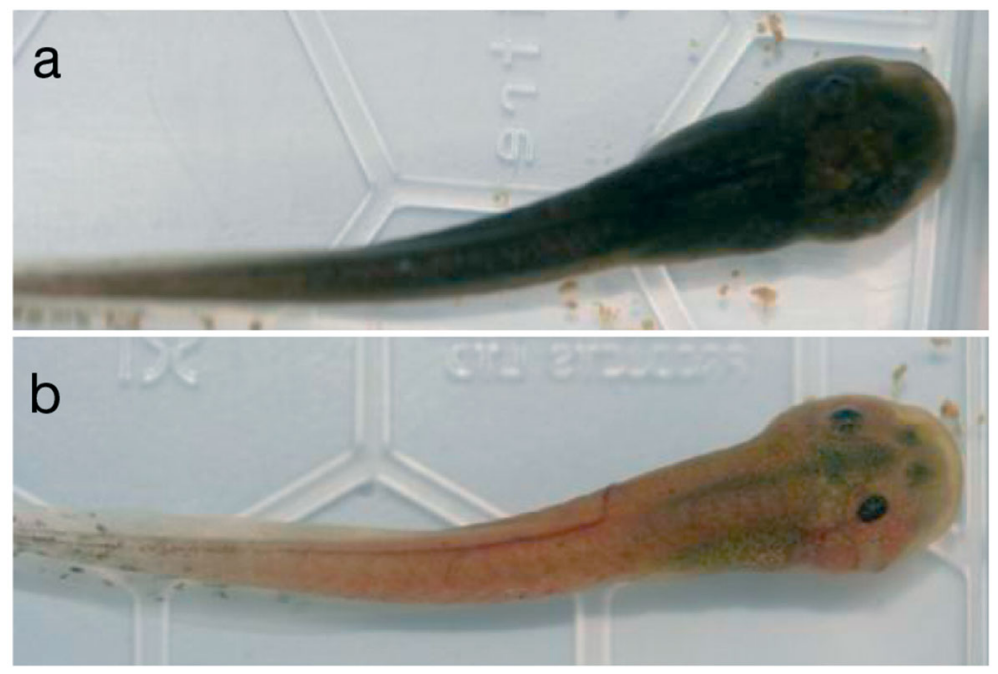

Fig. 1. Alytes muletensis. Examples of observed pigmentation variation. (a) Untreated tadpole with typical pigmentation. (b) Tadpole exposed for $7 \mathrm{~d}$ to $1.0 \mathrm{mg} \mathrm{l}^{-1}$ itraconazole exhibiting depigmentation

solution (i.e. 'panic' swimming), and often attempted to forage on the floor of the bath container. Tadpoles did exhibit significant depigmentation in all itraconazole treatments (Fig. 1) and some depigmentation in the $B d$-positive controls; however, we did not record which individuals appeared depigmented in which treatments, and cannot state irrefutably that specific treatment(s) did not result in depigmentation. As these observations were unpredicted, opportunistic and anecdotal, we were unable to perform any statistical comparisons among treatments.

\section{DISCUSSION}

Itraconazole appears to be a reliable antifungal for the elimination of $B d$ infection from Alytes muletensis tadpoles given our experimental design. No sign of $B d$ could be ascertained from any of our antifungal treatment specimens. This is unlikely to be due to any host immunological response, as our positive control individuals exhibited infection throughout the course of the experiment and infection burdens increased in the latter stages of the experiment. Other researchers have also had success with itraconazole as a treatment. Nichols \& Lamirande (2000) used a $0.01 \%$ solution in $0.6 \%$ saline over $11 \mathrm{~d}$ of $5 \mathrm{~min}$ treatments to successfully eliminate infection in juvenile blue-and-yellow poison dart frogs. Only $8 \mathrm{~d}$ of itraconazole baths resolved infection in subadult and adult individuals of the same species (Nichols \& Lamirande 2000). The only report describing the treatment of tadpoles is by Banks \& McCracken (2002), who report the inefficacy of Plistopur ${ }^{\circledR}$ (Sera) followed by griseofulvin against chytridiomycosis in sharp-snouted dayfrog tadpoles. To the best of our knowledge the present study is the first report of the use of itraconazole treatment for curing $B d$ infection in premetamorphic amphibians.

Itraconazole does not appear to be an irritant to Alytes muletensis tadpoles, as tadpoles did not appear agitated and exhibited foraging behaviour when exposed to all concentrations of the antifungal. Furthermore, tadpoles fed well after treatment, and no mortality, morbidity or lethargy was observed in any of the experimental tadpoles. Nevertheless, we cannot recommend itraconazole as a treatment for chytridiomycosis in larval A. muletensis without further testing, which is currently underway. The depigmentation we observed in our experimental tadpoles suggests that the production of melanin may in some way have been impaired by itraconazole treatment. Melanin is produced in many cells including the Kupffer cells in amphibian livers (Sichel et al. 2002). Additionally, hepatotoxic side effects of itraconazole have been reported in mammals (Collazos et al. 1995, Somchit et al. 2004); therefore, before itraconazole is adopted as a general treatment for larval amphibians, we suggest more research be undertaken to identify any potential side effects of this antifungal agent.

\section{LITERATURE CITED}

Andersen WC, Roybal JE, Turnipseed SB (2004) Determination of malachite green and leucomalachite green in salmon with in-situ oxidation and liquid chromatography with visible detection. US Food and Drug Administration Laboratory Information Bulletin no. 4334. www.cfsan.fda. gov/ acrobat/lib4334.pdf

Banks C, McCracken H (2002) Captive management and pathology of sharp snouted dayfrogs, Taudactylus acu- 
tirostris, at Melbourne and Taronga zoos. In: Natrass AEO (ed) Frogs in the community. Proceedings of the Brisbane Symposium. Queensland Frog Society, East Brisbane. Queensland Frog Society, Brisbane, p 94-102

Berger L, Speare R, Daszak P, Green DE and others (1998) Chytridiomycosis causes amphibian mortality associated with population declines in the rain forests of Australia and Central America. Proc Natl Acad Sci USA 95: 9031-9036

Bosch J, Martínez-Solano I (2006) Chytrid fungus infection related to unusual mortalities of Salamandra salamandra and Bufo bufo in Peñalara Natural Park, Spain. Oryx 40:84-89

Boyle DG, Boyle DB, Olsen V, Morgan JAT, Hyatt AD (2004) Rapid quantitative detection of chytridiomycosis (Batrachochytrium dendrobatidis) in amphibian samples using real-time Taqman PCR assay. Dis Aquat Org 60:141-148

Bridges CM, Semlitsch RD (2000) Variation in pesticide tolerance of tadpoles among and within species of Ranidae and patterns of amphibian decline. Conserv Biol 14:1490-1499

Collazos J, Mayo J, Martínez E, Díaz F (1995) Unusual liver toxicity due to the new antifungal agents fluconazole and itraconazole. Int Hepatol Commun 3:112-115

> Culp SJ, Beland FA (1996) Malachite green: a toxicological review. Int J Toxicol 15:219-238

> Fisher MC, Garner TWJ (2007) The relationship between the introduction of Batrachochytrium dendrobatidis, the international trade in amphibians and introduced amphibian species. Fungal Biol Rev 21:2-9

> Hadfield CA, Whitaker BR (2005) Amphibian emergency medicine and care. Semin Avian Exot Pet Med 14:79-89

La Marca E, Lips KR, Lötters S, Puschendorf R and others (2005) Catastrophic population declines and extinctions in neotropical harlequin frogs (Bufonidae: Atelopus). Biotropica 37:190-201

Marantelli G, Berger L, McInnes K (2000) Investigations into the treatment of Batrachochytrium in frogs and tadpoles. Proceedings of Workshop on Amphibian Disease, Cairns, August 2000. www.jcu.edu.au/school/phtm/PHTM/frogs/ gjabstra.htm (Abstract)

Mendelson JR III, Lips KR, Gagliardo RW, Rabb GB and oth-

Editorial responsibility: Alex Hyatt,

Geelong, Victoria, Australia ers (2006) Confronting amphibian declines and extinctions. Science 313:48

Nichols DK, Lamirande EW (2000) Treatment of cutaneous chytridiomycosis in blue-and-yellow poison dart frogs (Dendrobates tinctorius). Proceedings of Workshop on Amphibian Disease, Cairns, August 2000. www.jcu.edu. au/school/phtm/PHTM/frogs/gjabstra.htm (Abstract)

Nichols DK, Lamirande EW (2001) Successful treatment of chytridiomycosis. Froglog 46; www.open.ac.uk/daptf/ froglog/FROGLOG-46-1.html

Parker JM, Mikaelian I, Hahn N, Diggs HE (2002) Clinical diagnosis and treatment of epidermal chytridiomycosis in African clawed frogs (Xenopus tropicalis). Comp Med 52: $265-268$

> Pessier AP (2008) Management of disease as a threat to amphibian conservation. Int Zoo Yearb 42:30-39

Relyea RA (2003) Predator cues and pesticides: a double dose of danger. Ecol Appl 13:1515-1521

Schloegel LM, Hero JM, Berger L, Speare R, McDonald K, Daszak P (2006) The decline of the sharp-snouted day frog (Taudactylus acutirostris): The first documented case of extinction by infection in a free-ranging wildlife species? EcoHealth 3:35-40

Sichel G, Scalia M, Corsaro C (2002) Amphibia Kupffer cells. Microsc Res Tech 57:477-490

Skerratt LF, Berger L, Speare R, Cashins S and others (2007) Spread of chytridiomycosis has caused the rapid global decline and extinction of frogs. EcoHealth 4:125-134

Somchit N, Norshahida AR, Hasiah AH, Zuraini A, Sulaiman MR, Noordin MM (2004) Hepatotoxicity induced by antifungal drugs itraconazole and fluconazole in rats: a comparative in vivo study. Hum Exp Toxicol 23:519-525

Walker SF, Bosch J, James TY, Litvintseva AP and others (2008) Invasive pathogens threaten species recovery programs. Curr Biol 18:R853-R854

White AW (2006) A trial using salt to protect green and golden bell frogs from chytrid infection. Herpetofauna 36:93-96

Woodhams DC, Alford RA, Marantelli G (2003) Emerging disease of amphibians cured by elevated body temperature. Dis Aquat Org 55:65-67

Submitted: March 25, 2008; Accepted: November 1, 2008 Proofs received from author(s): February 18, 2009 